\title{
Injury Profile of Musicians in the Bloemfontein- based Free State Symphony Orchestra: A Short Report
}

\begin{abstract}
Similar to professional athletes, musicians are required to perform optimally. Few studies have been conducted to clarify the nature of injuries associated with musicians. This study aimed to determine the types of injuries and their prevalence amongst the musicians of the Free State Symphony Orchestra (FSSO), contributing factors, the musicians' response to injury, and their perception of physiotherapy. Forty-five members of the FSSO participated in this descriptive study. Analysis of data included frequencies and percentages for categorical data and percentiles for continuous data. Thirty-eight (84.4\%) participants reported injuries related to playing their instruments. Insufficient resting periods during playing sessions (70.3\%), continuing to play while experiencing symptoms (63.2\%) and performing the same movement repetitively (64.9\%) were identified as the perceived risk factors in the development of

\begin{tabular}{|c|}
\hline \\
Barnes R, MSc \\
Attwood H, BSc \\
Blom J, BSc \\
Jankielsohn S, BSc \\
Janse van Rensburg W, BSc \\
Smith T, BSc \\
Van Ede L, BSc \\
Nel M, MSc \\
University of the Free State \\
\hline
\end{tabular}
symptoms. Seventeen (44.7\%) participants indicated that they did nothing to relieve their symptoms, while $34.2 \%$ sought physiotherapy treatment, $31.6 \%$ took medication to alleviate their symptoms and $31.6 \%$ reduced their playing hours. Majority of participants (75\%) felt that their symptoms could be relieved by physiotherapy. Injuries amongst musicians result from a combination of factors such as posture, repetitive movements and fatigue. Possible physiotherapeutic intervention identified included educating musicians on the advantages of early management of injuries in extending their professional careers.
\end{abstract}

\section{KEY WORDS: INJURY PROFILE, MUSICIANS, SYMPHONY ORCHESTRA, CLASSICAL INSTRUMENTS,} SOUTH AFRICA.

\section{INTRODUCTION}

Robert Schumann wrote in 1838 (as cited by Fedak, 2006), "All the music is complete and alive within me, so that I wish to effortlessly breathe it out, but now I can hardly bring it forth; I trip over one finger with the other. This is truly frightening and has already caused me much pain". Schumann's statement epitomises the emotion of every musician that suffers from a condition that impedes their ability to express their musical idea. Very few studies have been performed to investigate the prevalence of injuries occurring in musicians. A survey of the International Conference of Symphony and Opera Musicians showed that $76 \%$ of symphony and opera musicians had at least one problem severe enough to interfere with their ability to perform (Fedak 2006).

No reports on studies relating to the type and prevalence of injuries in musicians in South Africa could be located.
The aim of our investigation was to determine the types of injuries and their prevalence amongst the musicians of the Free State Symphony Orchestra (FSSO) located in Bloemfontein, South Africa, the perceived contributing factors, the responses of the musicians to injury, and their perception of physiotherapy. By determining the injury profile of musicians, existing treatment regimens could be adapted specifically for musicians to enhance the effectiveness of treatment.

\section{METHODOLOGY}

\section{Study design}

An objective, descriptive study by means of a structured interview using a questionnaire, was conducted. The questionnaire was compiled from available literature (Bragge \& Bialocerkowski 2006; Steven \& Gregory 2002; Westrup \& Harrison 1976; Zaza 1998), as well as verbal information provided by the
Music Department of the University of the Free State (UFS), and the director of the FSSO.

\section{Pilot study}

After obtaining approval from the Ethics Committee of the Faculty of Health Sciences, UFS, a pilot study on six students enrolled at the Music Department of the UFS, who were not current members of the FSSO, was performed to enhance the face- and content validity of the questionnaire.
Corresponding Author:
Roline Barnes
Department of Physiotherapy (G30)
Faculty of Health Sciences
University of the Free State
PO Box 339 Bloemfontein
9300
South Africa
E-mail: BarnesRY@ufs.ac.za 


\section{Study population}

The study population included all individuals who were members of the FSSO at the time of the study. Of the $\mathrm{n}=50$ members of the orchestra, $\mathrm{n}=45$ $(90 \%)$ participated in the study.

\section{Method}

The structured interviews using the developed questionnaire were conducted in the presence of two researchers in order to ensure objectivity of questioning and to verify the information obtained. All information provided by the participants was handled with strict confidentiality.

\section{Statistical analysis}

Statistical analysis of data was done by the Department of Biostatistics, UFS, using frequencies and percentages for categorical data and percentiles for continuous data as well as $95 \%$ confidence interval for the prevalence.

\section{RESULTS}

Forty-five participants $(n=45)$ took part in the study, of whom $60 \%$ were female. The age distribution ranged between
18 and 76 years (median age 24 years). Thirty-eight $(84.4 \%)$ musicians of the FSSO reported injuries perceived to be related to playing their instrument $(95 \%$ confidence interval for the prevalence $[71.2 \% ; 92.3 \%])$, while $44.7 \%$ were also injured during an unrelated activity. The majority of participants $64.7 \%$ indicated that playing their instruments exacerbated their symptoms.

The rest of the results presented in this paper will be for the 38 musicians whose injuries were associated with playing their instruments. With regard to the nature of symptoms, aching pain was reported most frequently $(47.4 \%)$, followed by deep pain $(44.7 \%)$, stiffness $(39.5 \%)$, numbness $(31.6 \%)$ and stabbing pain $(31.6 \%)$. It was found that $47.4 \%$ of participants experienced symptoms of injury during and after playing the instrument, suggesting that the musician's musical performance was possibly affected by the injury. Insufficient resting periods during sessions of play $(70.3 \%)$, continuing to play while experiencing symptoms (63.2\%) and performing the same movement repetitively $(64.9 \%)$ were perceived as the major risk factors contributing to the development of symptoms.

The results indicated that $44.7 \%$ of participants did nothing in response to the symptom. Only $34.2 \%$ of respondents indicated that they sought physiotherapy treatment, while $31.6 \%$ took medication to alleviate their symptoms and $31.6 \%$ reduced their playing hours. Forty percent of all the participants were aware of the Alexander technique as a means to prevent and/or alleviate play-related injuries and discomfort. Nevertheless, only five of these 18 participants indicated that they applied the technique while playing their instruments. A general opinion exists within the performance arts that "the show must go on" and that pain and other symptoms are a normal part of their playing career. It is possibly with this mindset that some participants $(21.1 \%)$ did not respond appropriately to their injuries. The majority of participants (75\%) felt that their symptoms could be relieved by physiotherapy. However, only $49 \%$ of musicians who suffered from play-

Table 1: The number of years participants played their instruments and number of hours per week spent on practicing.

\begin{tabular}{|c|c|c|c|c|c|c|c|c|c|}
\hline \multirow{2}{*}{ Instrument } & \multirow{2}{*}{ Frequency } & \multirow{2}{*}{$\%$} & \multicolumn{3}{|c|}{ Position while playing (\%) } & \multicolumn{2}{|c|}{ Years playing } & \multicolumn{2}{|c|}{ Hours played per week } \\
\hline & & & Sitting & Standing & Combination & Range & Median & Range & Median \\
\hline Bass drum & 1 & 2.2 & & 2.2 & & 36 & 36 & 11 & 11 \\
\hline Bassoon & 2 & 4.4 & 2.2 & & 2.2 & $12-26$ & 19 & $5-14$ & 9.5 \\
\hline Cello & 5 & 11.1 & 11.1 & & & $14-54$ & 34 & $4-21$ & 16 \\
\hline Clarinet & 3 & 6.6 & 4.4 & & 2.2 & $8-30$ & 9 & $6-12$ & 8 \\
\hline Cymbals & 1 & 2.2 & 2.2 & & & 16 & 16 & 1 & 1 \\
\hline Double bass & 1 & 2.2 & 2.2 & & & 39 & 39 & 10 & 10 \\
\hline Flute & 4 & 8.8 & 4.4 & & 4.4 & $7-25$ & 15 & $7-20$ & 10 \\
\hline French horn & 1 & 2.2 & 2.2 & & & 10 & 10 & 5 & 5 \\
\hline Oboe & 1 & 2.2 & 2.2 & & & 28 & 28 & 1 & 1 \\
\hline Piano & 13 & 28.9 & 28.9 & & & $10-70$ & 20 & $1-72$ & 8 \\
\hline Saxophone & 3 & 6.7 & 6.7 & & & $5-14$ & 10 & $1-8$ & 2 \\
\hline Snare drum & 2 & 4.4 & & 4.4 & & $16-36$ & 26 & $11-20$ & 15.5 \\
\hline Timpani & 2 & 4.4 & 2.2 & 2.2 & & $16-36$ & 26 & $1-11$ & 6 \\
\hline Triangle & 2 & 4.4 & & 4.4 & & $16-36$ & 26 & $1-11$ & 6 \\
\hline Trombone & 2 & 4.4 & 4.4 & & & $3-8$ & 5.5 & $5-7$ & 6 \\
\hline Trumpet & 6 & 13.3 & 2.2 & 2.2 & 8.9 & $7-12$ & 9 & $6-20$ & 11.5 \\
\hline Viola & 6 & 13.4 & 6.7 & & 6.7 & $2-52$ & 24.5 & $2-28$ & 13 \\
\hline Violin & 14 & 31 & 4.4 & 2.2 & 24.4 & $6-70$ & 14 & $0-25$ & 8 \\
\hline Other & 6 & 13.3 & 11.1 & 2.2 & & $2-40$ & 10.5 & $3-48$ & 10 \\
\hline
\end{tabular}


related injuries sought physiotherapy treatment, and $76.9 \%$ of them indicated that physiotherapy helped to alleviate their symptoms.

\section{DISCUSSION}

Musicians as a group of professionals may incur various injuries. Some musicians, however, assume that injuries are a normal part of performance and find ways to mask the effects of a developing injury (Marxhausen 2006). Our findings indicated that $63.2 \%$ of the participants in this study continued to play while experiencing symptoms, supporting Marxhausen's statement.

Repetitive strain due to prolonged playing hours may contribute to poor posture and subsequently to possible injury. This correlating risk factor was identified in studies done by Castleman (2002), Fourie (2006) and Milanese (2000), and could be considered as a predisposing factor for developing some sort of injury related to playing an instrument. In addition, faulty technique, poor posture, and physical and playingrelated stress may also contribute to symptoms. Poor fitness levels or physical condition present definite risk, as structural weakness and other physical limitations may predispose musicians

Table 2. Action taken by participants $(n=38)$ in response to symptoms experienced while playing their instruments.

\begin{tabular}{|l|l|}
\hline Response to symptoms & Frequency $\mathbf{n}(\%)$ \\
\hline Did nothing & $17(44.7)$ \\
\hline Sought physiotherapy & $13(34.2)$ \\
\hline Took medication & $12(31.6)$ \\
\hline Reduced playing hours & $12(31.6)$ \\
\hline Consulted a doctor & $9(23.7)$ \\
\hline Had diagnostic imaging & $5(13.2)$ \\
\hline Used braces, splints or other orthosis & $4(10.5)$ \\
\hline Took time off (not playing instrument) & $5(13.2)$ \\
\hline Sought alternative treatment & $2(5.3)$ \\
\hline Followed an exercise or posture programme & $2(5.3)$ \\
\hline Underwent surgery & $2(5.3)$ \\
\hline Modified playing technique & $1(2.6)$ \\
\hline Alexander technique (n=18) & $5(27.8)$ \\
\hline
\end{tabular}

*Eighteen participants were aware of the Alexander technique, of whom five applied the technique. to PRMDs (Davies \& Mangion 2002; Meinke 1998).

Our observation that only five of 18 participants who were aware of the Alexander technique actually applied this technique could possibly be attributed to many of them never receiving proper training in the use of the technique. The benefits of the Alexander technique could be used by physiotherapists to address re-education of posture, retraining of muscles involved in core stability and pain relief. (Jones s.a.).

The high prevalence of injuries found in our study (i.e. $89.6 \%$ ) corresponded with a survey by the International Conference of Symphony and Opera Musicians, which showed that $76 \%$ of symphony musicians had at least one problem severe enough to interfere with their ability to perform (Fedak 2006). The repetition of specific movements and extended periods of continuous play also increase the likelihood of playrelated injury (Dawson 2002). However, this statement is negated by Fourie (2006) and Meinke (1998), who argue that repetition by itself is insufficient to cause symptoms, but that tension while playing the instrument stimulates a co-contraction that usually inhibits the smooth performance of rapid motion (Jones s.a.). Further research could also be done to investigate the effect or influence of poor posture and core stability, reduced endurance of muscles and poor proximal control on the development of play-related injuries and whether a direct association exists between the physical fitness and/or strength of the musician and their predisposition to injuries.

Certain limitations of the study need to be noted. The questionnaire did not make provision to record the duration of symptoms, whether symptoms were acute or chronic, whether symptoms prevented the musician from performing and if so, for how long. The link between a specific site of injury and the type of instrument played was also not determined, nor did the questionnaire enquire whether a physician was consulted due 
to the injury. These issues should be taken into account in future studies.

In conclusion, the observations made in this study indicate a relatively high prevalence of injuries among members of the Free State Symphony Orchestra. Injuries to musicians result from a combination of factors such as posture, repetitive movements and fatigue. An awareness program could contribute to musicians' understanding of the role physiotherapy could play in their careers, especially when problems with injuries are addressed early.

\section{ACKNOWLEDGEMENTS}

The authors acknowledge the members of the FSSO who participated in the study, and Daleen Struwig, medical writer, Faculty of Health Sciences, UFS, for technical and editorial preparation of the report.

\section{REFERENCES}

Bragge P, Bialocerkowski A, McMeeken J. 2006 A systematic review of prevalence and risk factors associated with playing-related musculoskeletal disorders in pianists. Occupational Medicine 56(1): 28-38.
Castleman H. 2002 Five common causes of physical injury for violinists. Comments of a master teacher on approach to the instrument. Medical Problems of Performing Artists 17:128-130.

Davies J, Mangion S, December. 2002 Predictors of pain and other musculoskeletal symptoms among professional instrumental musicians: Elucidating Specific Effects. Medical Problems of Performing Arts 17:155-168.

Dawson WJ. 2002 Upper-extremity problems caused by playing specific instruments. Medical problems of Performing Arts: 17:135-140.

Fedak K. 2006 Cumulative trauma disorders in musicians. Available at http://www.musicians clinic.com (Accessed 22 July 2007).

Fourie W. 2006 Making music: a real pain in the neck. South African Music Teacher 143: 41-45.

Jones FP. sine anno Alexander technique for musicians. Available at http://www.alexander center.com/pa/musicjonesii.html (Accessed 24 July 2009).

Lederman RJ. 1994 AAEM Minimonograph \#43: Neuromuscular problems in the performing arts. Muscle \& Nerve 17:569-577.

Marxhausen M. 2006 Instrumental injuries. Available at http://www.eeshop.unl.edu/music. html (Accessed 24 July 2007).

Meinke WB. 1998 Risks and realities of musical performance. Medical Problems of Performing Arts: $13: 56-60$.
Milanese S. 2000 Provision of on-site physiotherapy services during the performance of Wagner's Ring Cycle by the Adelaide Symphony Orchestra: A model of early intervention for playing-related musculoskeletal disorders. Medical Problems of Performing Artists 15:107-110.

Steven L, Gregory F. 2002 Maladies in musicians. Southern Medical Journal 95:727-734.

Westrup J, Harrison FL. 1976 Collins Encyclopaedia of Music. Great Brittan: William Collins Sons \& Company Limited.

Yeung E, Chan W, Pan F, Sau P, Tsui M, Yu B, Zaza C. 1999 A survey of playing-related musculoskeletal problems among professional orchestral musicians in Hong Kong. Medical Problems of Performing Artists 14:43-46.

Zaza C. 1998 Playing-related musculoskeletal disorders in musicians: a systematic review of incidence and prevalence. Canadian Medical Association Journal 158:1019-1025. 